\title{
On Decision Sharing in Libraries: How Much Do We Know?
}

In recent years empirical studies have begun to appear on the decision sharing practices of executives in health and welfare agencies and managers in industrial firms. Two tentative conclusions can be drawn: (1) The typical high-level manager who has been studied does not employ a single decision making style but permits the circumstances to dictate whether a decision shall be one-sided, consultative, or delegative; (2) a considerable amount of decision sharing is permitted with subordinates. Similar and more extensively conceived research is needed on decision sharing in libraries; to this end a number of research problems are indicated. Additionally, several hypotheses are offered to provide the beginnings of a conceptual foundation for future research. $\mathbf{I}_{\mathrm{s}}$ SLAVE Genovese writes that the "Mammies" in the "Big House" acted the part of a "surrogate mistress," barking out orders, settling disputes among the servants in the mansion, and serving as "confidante to the children, the mistress and even the master." Among her other duties she taught the "courtesies to the white children as well as to those black children destined to work in the 'Big House!' "1

Power sharing, which Genovese is describing, takes various forms: delegation of authority is one; making decisions jointly between superior and subordinate is another; still a third kind takes place when a subordinate, permitted to give advice, exerts a decisive influence on a decision. In this essay answers to two important questions will be sought: How frequently is each of the decisionsharing styles employed, and what determines the choice of style?

In recent years empirical studies have begun to appear on the decision-sharing

Louis Kaplan is professor in the Library School, University of Wisconsin-Madison. practices of executives as well as on their attitudes toward sharing. Two major conclusions can be drawn from this literature. First, an executive does not employ a single style; depending on the circumstances, some of the decisions may be one-sided, while others may be delegated. Still others might be made jointly. As one scholar has written, "It makes more sense to talk about participative and autocratic situations than it does to talk about participative and autocratic managers." 2

The second conclusion (more tentative than the first) is that despite popular belief in the unbreakable chain of command in hierarchically structured organizations, superiors permit a considerable amount of influence to their subordinates. These conclusions will surprise those who still think of administrators in monolithic terms, yet much research has been published that is destructive of the monolithic image. Some executives, for example, are "people" oriented, while others are "task" oriented. ${ }^{3}$ Higher-level managers, we are informed, have a stronger desire for 
"power and authority in their position than do lower-level managers." 4 Among managers in differentiated positions all showed a strong desire to lead and to direct, but these desires were strongest among those in charge of sales and weakest among the presidents of the manufacturing companies studied. ${ }^{5}$ Even more noteworthy is the report that "inner-directed" persons (those whose conduct is not dominated by the desires of others) have been promoted to high positions in organizations. ${ }^{6}$

\section{A Note on Terminology}

In order to avoid the monotonous use of the term "decision sharing," two alternatives are employed, namely, "influence sharing" and "power sharing." Though not synonymous, the interchangeable use of these three terms within the meaning of this essay should not cause confusion. The terms, "executive," "administrator," and "manager," have taken on separate meanings, but the differences have little significance for this essay; for this reason these three terms, along with the word "leader," will be used as the context dictates.

\section{Studies on the Extent of POWER Sharing}

Two major studies have been published describing the power sharing practices of high-level American managers. One, by Heller, deals with 260 "senior" managers in fifteen large "successful" manufacturing firms. ${ }^{7}$ Though holding top-level positions, the subjects in this study were not presidents of their firms. The decisions of the subjects (as reported by themselves) related to their own work and to the work of their immediate managerial subordinates. The other publication, by Vroom and Yetton, tells of the decisions recalled by 268 managers "from a number of different firms." 8 As might be expected, the authors of these studies each employed a distinctive continuum of decision styles; nevertheless, a meaningful comparison of the two is possible.

Heller's continuum includes five styles, two of which encompass onesided decisions made without prior consultation. These two are clearly outside the scope of influence sharing. His third style is also one-sided, but this kind of decision is not made until after consultation. The fourth is dyadic, that is, both managers have approximately equal influence. Delegation is the fifth style in this continuum.

In the continuum constructed by Vroom and Yetton there are also five styles. The fifth, different from any found in Heller, is described below. In two of these styles, one-sided decisions are made without prior consultation. In the remaining two the decision is not made until after consultation: In one of these the subordinates are consulted individually; in the other they are consulted in a group.

Heller indicates that of the decisions made by the "senior" managers, 73 percent were one-sided, but of these 37 percent were preceded by consultation. The remaining 27 percent were either dyadic or delegated. In the interpretation of these statistics much depends on whether prior consultation is regarded as a kind of power sharing. In part, the answer rests on how often the subordinate managers "steered" the ultimate decision. On this point (as shown later), Heller can offer only an educated guess. ${ }^{9}$ In one respect, the executives studied by Vroom were much like those reported on by Heller: About three-fourths of their decisions were one-sided. However, of these, about 51 percent were made only after consultation (compared to 37 percent in the Heller study). The remaining 28 percent fell within Vroom's fifth style of decision making. In this style the superior sits with the subordinates, but does not try (at least openly) to steer the decision. In this setting the leader may define the problem or 
even indicate alternative solutions. When this happens, the decision cannot be said to have been delegated. More properly, when the superior participates to that extent, the decision is better described as dyadic. Actually, Vroom's fifth style is much like Heller's fourth and fifth in combination, and interestingly these were used with equal frequency. ${ }^{10}$

In his oft-cited book on management, Likert decried all one-sided decisions, including those that were delegated.11 Because he favored the dyadic, Likert would have approved of Vroom's fifth style only if the superior openly and fully shared in the making of decisions.

When and Why Do Superiors Permit

\section{Decision Sharing?}

On the question as to when and why leaders permit influence sharing, Heller's work opens new vistas. His findings are best understood when classified as organizational or personal. ${ }^{12}$ With regard to the organizational factors, Heller presented the following:

1. If the decision is perceived to be of great importance to the organization, the superior is likely to use a one-sided style.

2. If the decision is perceived to be important to the subordinate, the senior will likely use one of the three less autocratic styles.

3 . If the decision is believed to be of greater significance to the senior than to the subordinate, a onesided decision is likely to be made.

4. The greater the senior's "span" of control, the more likely will a timesaving style be employed, that is, autocratic or delegative.

Heller's findings are in part confirmed by Blau, who investigated fifty-three employment agencies in the United States. ${ }^{13}$ The greater the risk, said Blau, the more reluctant would management be to delegate decision making. What is more, there is a tendency to decentral- ize authority when the "large size of an organization expands the volume of managerial decisions beyond the capacity of the top executive and his deputy."14 Blau saw risk and size as the source of conflicting forces, size promoting decentralization of authority while risk worked in the opposite direction. ${ }^{15}$

According to Vroom, the most significant determinant of power sharing is the information needed to make a decision. If the senior believes no additional information is needed, a onesided style is likely to be employed. If, however, the senior believes that the subordinate has information necessary to the decision, a participative style is likely to be permitted. ${ }^{16}$

As to personal factors that shape the making of decisions, Heller reported:

1. When the senior perceives the skills of the subordinate to be inadequate, an authoritative style is likely to be used.

2. The greater the experience of the senior, the more likely will a powersharing style be employed.

3 . The older the senior, the more likely will a decision sharing style be employed. ${ }^{17}$

\section{AdDitional Studies Bearing on Power Sharing}

In a study of the "authoritarian" personality in organizations, Vroom noted that in a parcel-delivery company supervisors who were submissive had the least interest in sharing power. ${ }^{18}$

In their attitude towards participation American managers were found to be little different from those in England, but the Americans revealed less confidence in the skills of their subordinates. ${ }^{19}$ As already indicated, the perception of skills in subordinates, according to Heller, is an important factor in power sharing.

Students of organizational behavior have noted that the expectations of subordinates sometimes result in a larger 
degree of influence. ${ }^{20}$ Professional employees present a good example. Professors, according to Blau, exert much influence on educational policy in some universities. ${ }^{21}$ Those in the "semi-professions" (such as nurses and librarians), according to Hall, could expect to wield less influence than those in the more highly regarded professions. Furthermore, according to Hall, professionals in autonomous organizations (as opposed to those in organizations whose chief reports to a higher authority) perceive a greater amount of autonomy..$^{22}$

Hage and Aiken, who studied sixteen health and welfare agencies, wrote that power sharing is more likely found in those organizations with a larger number of occupational specialties and where the employees have received more extensive professional training. ${ }^{23}$ Blankenship and Miles investigated power sharing and autonomy among 190 managers in eight organizations (mainly in the electronics industry). On the question of their opportunities to influence decisions, 67 percent of those in the upper levels of management replied in the affirmative, compared to 51 percent of those in the middle range, and to 29 percent of those in the lower levels. Eighty percent of the upper-level managers compared to 40 percent of the middle and lower managers reported freedom to make "ultimate" decisions. ${ }^{24}$

In still another study, Mechanic affirmed that subordinates can win power by possession of expert knowledge or through propinquity to those in command..$^{25}$ An example of this is the administrative assistant to a chief librarian.

\section{Research NeEdS}

Two styles in the continuum used by Heller require further explication. These are "prior consultation" and "delegation." As Sherman has noted, it is important to identify the specific kind of delegation in question: Is it authority granted without accountability?26 Heller has more recently come to see the need to identify delegation more precisely; he would distinguish between delegation that calls for immediate or delayed ac-

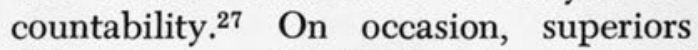
delegate to subordinates the task of gathering information: Is this to be construed as a form of prior consultation? As for "prior consultation," is it possible clearly to differentiate between this style and decisions made jointly?

Heller writes that senior and subordinate managers had different perceptions of the styles of decisions being employed even though they were both reporting on the same decisions. Sometimes, for example, if the senior reported a one-sided decision preceded by consultation, the subordinate might report that decision to have been made jointly, or even delegated. Heller hypothesized that subordinates yearn for more influence than is permitted, which would account for the differences in perception. ${ }^{28}$ But an additional explanation is possible, namely, that there was no clear understanding of the different styles.

In a study of managerial attitudes in a number of countries, Haire showed that American and English managers were favorably disposed toward participation; Haire then went on to claim, without evidence, that there was a gap between the stated attitudes of the Americans and their actual behavior, which, according to Haire, was generally authoritative. Haire explained the gap by pointing to the American democratic creed that effectively shut off public expression of undemocratic opinions. ${ }^{29}$ But despite Haire, Heller found that the Americans and the English used his various decision styles with approximately the same frequency. ${ }^{30}$ To this evidence Haire could reply that neither, on the record, is particularly democratic, considering that of the decisions made, little more than 25 percent were indisputably nonautocratic. 
One of the weaknesses of the investigations by Heller and Vroom is that the managers were relied upon to recall the decision styles actually used. What is needed is studies in which decisions are recorded as they are made; unfortunately, gaining permission to do so is no simple matter. Heller's study, it is true, does lend partial credence to the accuracy of the reporting by the senior managers. Although he found other discrepancies between the reporting of the seniors and the subordinates, the two were in agreement with respect to the two autocratic styles (which were least likely to be misconstrued) ${ }^{31}$

Studies are needed on the subject of sharing decisions with groups as contrasted with individuals. Vroom distinguished between sharing a problem with subordinates separately or in a group, and he found that conferring with a group was preferred. ${ }^{32}$ Within the process of consulting with a group is it possible to recognize a decision made jointly? If the superior clearly reveals a preference, can the outcome be regarded as dyadic? Based on a laboratory-type experiment, when the leader reveals a solution, the opinions of those in the group "coalesce." 33

Heller studied only high-level executives. How different are those lower in the hierarchy? Do supervisors in libraries at lower levels experience little autonomy and few opportunities to give advice? And if so, what is the explanation? Is it true that top-level administrators are too busy coordinating and planning to monopolize the making of decisions? Is it possible that supervisors at the lower levels, less occupied, have more time for decisions?

In a study of library departments, Lynch attempted (without success) to find a meaningful relationship between degree of "routinization" and the amount of discretion given to workers. ${ }^{34}$ Lynch attempted to measure discretion through worker responses. Perhaps a study such as Heller conducted, that is, based on supervisory decisions, might yield more positive results.

Heller has shown that managers in industry responsible for personnel work are less willing to share power than are those in production. ${ }^{35}$ From this point of view a study of catalog departments might be especially revealing: Here is found a high degree of routinization and workers engaged in production.

Tannenbaum claims with respect to industrial workers in the U.S. that though they lack control of broad policy issues, "they do have informal influence through superiors concerning aspects of their daily work life." ${ }^{36} \mathrm{Can}$ the same be said of librarians? If not, is it unionization that accounts for the difference?

In a continuum conceived prior to Heller's, there were included those decisions that executives make tentatively, subject to discussion. ${ }^{37}$ On a related point, Heller wrote that on the basis of an educated guess, "it is likely that up to half the decisions following consultation reflect the subordinate's influence." 38 On this point empirical evidence would be welcome, as would knowledge of how frequently decisions made tentatively are revised following consultation.

Span of control has a special significance to librarians, given the large number of branch libraries that have been established. Where there is a large number of these do the branch librarians enjoy a considerable amount of autonomy? Is the situation different when the number is not large?

In profit-making firms, decisions involving risk must be frequently made. Does "risk" in the library setting play an important role in the choice of decision styles?

Currently, librarians are trying to promote participation. Is it possible to identify those models of participation (UCLA? Columbia? Cornell? Miami?) 
that are productive of the largest amount of decision sharing?

\section{ConcLusion}

Two points of view are possible (given the present indeterminate state of knowledge) with respect to libraries as a type of organization: either libraries are greatly different, or else they have much in common with other organizations.

My view is that libraries have fewer differences than similarities: among the significant similarities are a complex and hierarchical structure, a variety of professional specialties, and a mixture of professionals, subprofessionals, and nonprofessionals. Obviously, if these similarities are indeed significant, then libraries have much in common not only with hospitals and social work agencies, but with many industrial firms as well.

The question of differences and similarities has significance only because some persons argue that decision making in libraries bears no relationship or resemblance to most other organizations, and especially not to industrial firms. This is a matter that can be settled only through research, but it is not merely to settle this debate that research is needed.

Much of the library literature on participation, for example, could be explicated through a study of decision making styles among librarians. Still another example is the problem of autonomy for professionals (such as librarians) who work in heteronomous organizations. Is a lesser degree of autonomy inevitable for librarians? Is it possible, for example, that a democratic type of university administration will tend to produce the same kind of administration in that university's library? And still another: given the importance of supervisors at the lower levels of management, do we not need to know their decision styles?

Finally, to answer the question found in the title of this essay: how much do we know about decision sharing in libraries? Empirically, we know very little, but before empirical research is pursued a theory of decision making in libraries is needed. To the ultimate development of such a theory the propositions that follow may constitute a contribution. As is required of the component parts of a theory, each can be tested:

1. For several reasons (such as lesser risk), high-level library administrators will be found to use autocratic decision styles proportionately less frequently than do their counterparts in industry.

2. Investigators will find that proportionately fewer autocratic decisions are made in the less "routinized" library departments and in those units where the nonprofessionals are not overwhelmingly greater in number than the professionals.

3. In libraries where regulations are largely codified, departmental chiefs will be found to delegate a large proportion of those decisions that relate to the implementation of policies previously established. This proposition is based on Blau's study of the positive relationship of written regulations to nonautocratic styles. ${ }^{39}$

4. The greater the number of branch libraries and the greater the distances involved, the more frequently will the heads of branch libraries find decision making delegated to them.

5. Investigators will verify that there is no necessary clash between decision sharing and hierarchical structure. Tannenbaum, on the basis of empirical evidence, states that participation has a "mitigating effect" on authority in hierarchies and that in "effective participative" organizations superiors and subordinates are both influential even though there is a high total amount of control. ${ }^{40}$ 


\section{REFERENCES}

1. Eugene D. Genovese, Roll, Jordan, Roll (New York: Pantheon Books, 1972), p.35556.

2. Victor H. Vroom, "A New Look at Managerial Decision Making," Organizational Dynamics 1:77 (1973).

3. Cyril Sofer, Men in Mid-Career (Cambridge: Cambridge University Press, 1970), p.36. See also R. Blake and Jane Mouton, The Managerial Grid (Houston: Gulf, 1964).

4. Victor H. Vroom, Motivation in Management (New York: American Foundation for Management Research, 1965), p.28.

5. Vroom, Motivation in Management, p.2324.

6. Edward E. Lawler and Lyman W. Porter, "Antecedent Attitudes of Effective Managerial Performance," Organizational Behavior and Human Performance 2:141 (1967).

7. Frank A. Heller, Managerial Decision-Making (London: Tavistock, 1971).

8. Victor H. Vroom and Philip W. Yetton, Leadership and Decision-Making (Pittsburgh: Univ. of Pittsburgh Pr., 1973), p.74-78.

9. Heller, Managerial Decision-Making, p.xvi, 106.

10. Vroom and Yetton, Leadership and Decision-Making, p.13, 139.

11. Rensis Likert, New Patterns of Management (New York: McGraw-Hill, 1961), p.229.

12. Heller, Managerial Decision-Making, p.xvi$\mathrm{xx}, 83-84,105-8$.

13. Peter M. Blau, "Decentralization in Bureaucracies," in Mayer N. Zald, ed., Power in Organizations (Nashville: Vanderbilt Univ. Pr., 1970), p.150-76.

14. Ibid., p. 168-69.

15. Ibid., p. 171.

16. Vroom and Yetton, Leadership and Decision-Making, p.83-84.

17. Heller, Managerial Decision-Making, p.xix.

18. Victor H. Vroom, "Some Personality Determinants of the Effects of Participation," Journal of Abnormal and Social Psychology 59:322-27 (1959).

19. Heller, Managerial Decision-Making, p.56.

20. Bruce R. Crowe, "The Effects of Subordinates' Behaviour on Managerial Style," $\mathrm{Hu}$ man Relations 25:215-37 (1972).

21. Peter M. Blau, The Organization of Academic Work (New York: John Wiley, 1973 ), p.184-88.
22. Richard H. Hall, "Some Organizational Considerations in the Professional-Organizational Relationship," Administrative Science Quarterly 12:461-78 (1967).

23. Jerald Hage and Michael Aiken, "Relationship of Centralization to Other Structural Properties," Administrative Science Quarterly 12:72-92 (1967).

24. L. Vaughn Blankenship and Raymond E. Miles, "Organizational Structure and Managerial Decision Behavior," Administrative Science Quarterly 13:106-20 (1968).

25. David Mechanic, "Sources of Power of Lower Participants in Complex Organizations," Administrative Science Quarterly 7: 249-64 (1962).

26. Harvey Sherman, It All Depends (University, Alabama: Univ. of Alabama Pr., 1966), p.82-87.

27. Frank A. Heller, "Leadership, DecisionMaking, and Contingency Theory," Industrial Relations 12:189 (1973).

28. Heller, Managerial Decision-Making, p.xvii, 73.

29. Mason Haire, and others, Management Thinking: An International Study (New York: John Wiley, 1966), p.22, 172.

30. Heller, Managerial Decision-Making, p.84. For the comparison with the English managers, see Heller, "Leadership, Decision Making and Contingency Theory,” p.196.

31. Heller, Managerial Decision-Making, p.73, 106.

32. Vroom and Yetton, Leadership and Decision-Making, p.139.

33. Bernard M. Bass, "Some Effects on a Group of Whether and When the Head Reveals His Opinion," Occupational Behavior and Human Performance 2:375-81 (1967).

34. Beverly P. Lynch, "A Framework for a Comparative Analysis of Library Work," College \& Research Libraries 35:432-43 (1974).

35. Heller, "Leadership, Decision Making and Contingency Theory," p.197.

36. Arnold S. Tannenbaum, and others, Hierarchy in Organizations (San Francisco: Jossey-Bass, 1974), p.61.

37. Robert Tannenbaum, "How to Choose a Leadership Pattern," Harvard Business Review 36:95-101 (March/April, 1958).

38. Heller, Managerial Decision-Making, p.xvi.

39. Peter M. Blau, The Structure of Organizations (New York: Basic Books, 1971), p.115-19.

40. Tannenbaum, Hierarchy in Organizations, p.195, 205. 